\title{
Estigma, experimentação e risco: A questão do álcool e das drogas na cena punk
}

Stigma, Experimentation and Risk: Alcohol and Drugs in the Punk Scene

Stigmate, essai et risque: La question de l'alcool et des drogues dans la scène punk

Paula Guerra, Tânia Moreira e Augusto Santos Silva

\section{OpenEdition}

\section{Journals}

Edição electrónica

URL: http://journals.openedition.org/rccs/6206

DOI: $10.4000 /$ rccs.6206

ISSN: 2182-7435

\section{Editora}

Centro de Estudos Sociais da Universidade de Coimbra

Edição impressa

Data de publição: 1 Maio 2016

Paginação: 33-62

ISSN: 0254-1106

\section{Refêrencia eletrónica}

Paula Guerra, Tânia Moreira e Augusto Santos Silva, «Estigma, experimentação e risco: A questão do álcool e das drogas na cena punk », Revista Crítica de Ciências Sociais [Online], 109 | 2016, colocado online no dia 18 maio 2016, criado a 01 maio 2019. URL : http://journals.openedition.org/rccs/6206 ; DOI : $10.4000 /$ rccs. 6206 


\title{
PAULA GUERRA, TÂNIA MOREIRA, AUGUSTO SANTOS SILVA
}

\section{Estigma, experimentação e risco: A questão do álcool e das drogas na cena punk}

\begin{abstract}
As drogas constituem eixos referenciais do rock ' $n$ ' roll em geral e do punk rock em particular. Assim, não será casual a reiterada presença do álcool e das drogas nos discursos dos protagonistas e nas canções do punk português. Este artigo considera-a menos do ponto de vista das práticas e contextos de consumo, e mais do ponto de vista dos discursos produzidos, dentro da cena, sobre o sentido do uso e o risco da dependência. O material empírico com que trabalha é constituído pelos depoimentos de 214 atores punk entrevistados entre 2012 e 2014 e pelas letras das canções que eles consideraram como mais influentes na cena. O artigo aborda três tópicos centrais: 1) a representação da natureza da relação com o álcool e as drogas; 2) a sua centralidade como questão identitária, isto é, respeitante ao nome, à coesão e ao posicionamento da cena; e 3) a diversidade das atitudes e discursos que nela circulam.
\end{abstract}

Palavras-chave: culturas juvenis; música portuguesa; música punk rock; música rock; sociologia da música.

\section{Introdução}

Este artigo decorre de uma investigação levada a cabo nos últimos três anos em torno das manifestações punk na sociedade portuguesa entre 1977 e $2015^{1}$ e no quadro da discussão alargada das culturas juvenis na modernidade tardia ocidental. A partir do seu surgimento mediático nos finais dos anos 1970, o punk transformou-se num fenómeno global com traduções locais mais ou menos expressivas: o punk não é só inglês ou americano, mas é também português - e é disso que trata o referido projeto de investigação (Guerra, 2014).

\footnotetext{
${ }^{1}$ O projeto Keep It Simple, Make It Fast! (doravante, KISMIF), cofinanciado por fundos nacionais através da Fundação para a Ciência e a Tecnologia e por fundos FEDER (através do programa operacional COMPETE), desenvolvido no Instituto de Sociologia da Universidade do Porto, em parceria com o Griffith Centre for Cultural Research da Universidade de Griffith e a Universitat de Lleida. O KISMIF conta ainda com a participação das Faculdades de Economia e de Psicologia e de Ciências da Educação da Universidade do Porto, da Faculdade de Economia e do Centro de Estudos Sociais da Universidade de Coimbra e das Bibliotecas Municipais de Lisboa.
} 
Ele recorreu a três abordagens fundamentais (Silva e Guerra, 2015). A primeira foi a recolha tão sistemática quanto possível das fontes documentais do punk e suas manifestações: os discos e outros registos fonográficos (quer o seu conteúdo musical, quer a sua forma gráfica), os cartazes, programas e outros instrumentos de divulgação, os fanzines e outros boletins e meios impressos, as notícias e relatos, e mais recentemente, os registos vídeo. A segunda abordagem baseia-se nos testemunhos, recolhidos através de entrevistas em profundidade (num total de 214 e algumas revestindo a forma de histórias de vida) a pessoas de algum modo envolvidas na cena punk, atualmente ou em fases anteriores de percurso. Pessoas que são ou foram músicos, a título amador, semiprofissional ou profissional, promotores, editores, agentes, divulgadores, críticos, consumidores, fãs, colecionadores, e que trazem com os seus relatos uma reflexão sobre a própria experiência, assim como a interpretação da cena ou do mundo a partir dela. A terceira abordagem, finalmente, consubstancia-se na observação de contextos e acontecimentos contemporâneos que possam ser relacionados com o punk, com destaque para os festivais e outros eventos musicais de menor dimensão, e através da sua observação direta, de registos visuais e de inquéritos por questionário aos respetivos espectadores.

O objetivo, neste artigo, é a consideração das representações veiculadas por atores e canções ${ }^{2}$ em torno das drogas e do álcool, e a partir de três temas fundamentais: experimentação, risco e estigma. Experimentação de novos consumos numa sociedade fechada à diferença por parte de um conjunto de jovens que queriam a diferença; riscos como consequências físicas e psicológicas negativas sobre o próprio e os seus semelhantes (Beck, 1992; Giddens, 1991); e estigma como risco de exclusão, de etiquetagem com um rótulo socialmente desvalorizado, excludente e marginal (Becker, 1985). É das escolhas de risco dos atores estudados que tratam estes discursos sobre droga e álcool no punk português. Tal não equivale a associar as drogas ou o álcool ao punk, poderia ser outra (sub)cultura, outra cena, mas tão-só a mostrar a sua importância nas perceções acerca desta cena. Daqui advém ainda o conceito de drogas utilizado ao longo deste artigo: trata-se não de um conceito farmacológico ou derivado do seu uso, mas de uma concetualização focada nas dimensões social e culturalmente construídas das drogas e do álcool, bem como das reações societais que suscitam.

\footnotetext{
${ }^{2}$ Não analisámos todas as canções, mas as que foram identificadas pelo conjunto dos 214 entrevistados como as mais relevantes do punk português. Portanto, no caso particular deste artigo, relevamos o segundo eixo de abordagem, as entrevistas em profundidade realizadas e os seus conteúdos.
} 
Assim, para a abordagem das representações acerca das drogas (e álcool), relevamos as 214 entrevistas em profundidade ${ }^{3}$ realizadas aos atores que consideram pertencer ou ter pertencido, sob diversos papéis, à cena punk; e as 264 canções que eles assumiram como mais significativas de tal cena. Mais de dois terços dos entrevistados pertencem à cena como músicos: $45 \%$ como músicos em atividade, $24 \%$ como músicos retirados. Quase metade tem experiência de intermediação, por via sobretudo da edição fonográfica: $34 \%$ ativos, $13 \%$ retirados. $24 \%$ afirmam-se fãs, consumidores informados e fiéis. A combinação de papéis é a norma para dois quintos, com destaque para os que são, ao mesmo tempo, músicos e mediadores (20\%) e ex-músicos e fãs (10\%). O conjunto é marcadamente masculino, só $14 \%$ sendo mulheres; adulto, com a idade média de 40 anos; urbano, residindo 44\% na Grande Lisboa, 16\% no Grande Porto e 9\% na Península de Setúbal; escolarizado, tendo $41 \%$ instrução superior e $40 \%$ instrução secundária; oriundo preferencialmente das classes médias e superiores, com $24 \%$ de profissionais intelectuais e científicos, $22 \%$ de profissionais liberais e $13 \%$ de profissionais técnicos e de enquadramento intermédio (Abreu et al., 2016).

O conceito de cena cultural desenvolve-se a partir dos conceitos de campo, tal como proposto por Pierre Bourdieu, e de mundo da arte, tal como proposto por Howard S. Becker (cf. Bennett e Peterson, 2004: 3). De acordo com vários autores, este conceito permite uma boa articulação entre as dimensões local e global das dinâmicas contemporâneas. Ele surge no âmbito das teorias apelidadas de post subcultural studies, para designar determinados clusters de atividades socioculturais, as quais se agregam pela sua localização (normalmente um bairro, uma cidade ou área urbana) e/ /ou pelo tipo de produção cultural (por exemplo, um estilo de música) (Bennett e Peterson, 2004: 223; Straw, 1991). O trabalho de Straw, em 1991, foi seminal. Ele construiu uma análise sofisticada da interação da música com o gosto e a identidade, explorando a ideia de translocalismo, isto é, que clusters de agentes musicais geograficamente dispersos podem envolver-se em práticas culturais coletivas graças à capacidade que a música tem de

\footnotetext{
3 A amostra foi construída pelo método da bola de neve, seguindo as redes de contactos entre os atores, a partir de uma base inicial referenciada pela equipa de investigação. Procurou ser o mais abrangente possível em termos de geração de vida, de género, de espaço, de papéis e de subgéneros punk (cf. Abreu et al., 2016). Os 214 entrevistados do projeto KISMIF têm em comum a participação, presente e/ou passada, na cena punk portuguesa: ou como músicos, ou como promotores, editores, críticos e outros intermediários, ou como consumidores. As entrevistas foram orientadas por um guião com mais de 50 entradas categoriais, sendo uma delas referente à representação das drogas e álcool na cena punk. portuguesa. As entrevistas foram transcritas e objeto de análise clássica de conteúdo e/ou de outros tratamentos de discurso de pendor quantitativo e/ou qualitativo.
} 
transcender as barreiras físicas. A partir de então, o conceito tem vindo a ser cada vez mais utilizado em análises sobre a produção, performance e receção da música popular, envolvendo coordenadas de tempo e espaço. É neste âmbito, e como alternativa ao mecanicismo do conceito de subcultura e ao anacronismo do conceito de movimento, que designamos o nosso objeto como a cena punk portuguesa (Guerra e Quintela, 2015; Guerra e Silva, 2015; Guerra e Bennett, 2015; Guerra, 2014).

\section{Rock, punk e "drogas"}

O álcool e as substâncias psicotrópicas de venda ilegal (às quais reservaremos, para aproveitar sociologicamente o uso comum, o termo de drogas), constituem eixos referenciais da cultura punk, tal como acontece com outras culturas musicais no pós-guerra (Brake, 1985; Savage, 2002). A investigação que serve de base a este artigo rapidamente constatou este facto, qualquer que fosse o ponto de observação privilegiado.

Dos 214 protagonistas da cena punk nacional entrevistados para o projeto, entre dezembro de 2012 e outubro de 2014, 168, ou seja, 79\%, abordam o tema. Fazem-no mulheres e homens, de qualquer nível de instrução. E a circunstância de ser entre os mais novos que a abordagem é proporcionalmente menos generalizada indica que este é um aspeto crítico da experiência de vida, sendo mais fácil falar dele quando pode ser recolocado na perspetiva de uma história pessoal e/ou geracional já em parte transcorrida. Indicia, ainda, uma grande permeabilidade das histórias individuais aos contextos vivenciais (Quadro 1).

QUADRO 1 - Presença do tema do álcool e das drogas nos depoimentos dos entrevistados do projeto KISMIF, segundo o género, a idade e o nível de instrução (em \%)

\begin{tabular}{lll}
\hline \multirow{2}{*}{ Género } & Feminino & 80,0 \\
\cline { 2 - 3 } & Masculino & 78,3 \\
\hline \multirow{3}{*}{ Idade } & $15-30$ anos & 65,8 \\
\cline { 2 - 3 } & $31-45$ anos & 83,5 \\
\cline { 2 - 3 } Nível de instrução & -45 anos & 77,6 \\
\hline \multirow{2}{*}{ Total } & Ensino básico & 83,3 \\
\cline { 2 - 3 } & Ensino secundário & 74,4 \\
\hline
\end{tabular}


Quando consideramos as canções das bandas punk, também notamos logo a presença regular do tema. Tendo solicitado a cada um/a dos 214 entrevistados a indicação de até 10 canções que considerasse serem influentes na cena, e obtendo assim um conjunto de 143 canções assinaladas por mais de $1 \%$ dos entrevistados, encontrámos referências diretas e explícitas a álcool e/ou drogas em mais de um quinto (22,3\%) das 130 canções cujas letras foi possível transcrever. E, se fizermos um exercício semelhante para os álbuns, verificaremos que 6\% das 113 capas e contracapas dos álbuns mais citados incluem símbolos conotando consumo de álcool com drogas (Silva e Guerra, 2015: 151).

Sem surpresa. É sabida a associação da cultura rock à experimentação e consumo de tais substâncias. O que se inscreve na mais longa tradição dita boémia dos círculos artísticos (que remonta, na versão moderna, ao século xix), mas apresenta também caraterísticas novas. Entre estas encontra-se a sua integração num mais amplo posicionamento anticonvencional por parte de juventudes urbanas, desafiando explicitamente normas sociais; assim como a orientação para o experimentalismo, forçando os limites do conhecimento consciente e desbravando novos caminhos de experiência sensorial, fundando o sentido da vida numa aceleração do tempo, na vivência intensa, rápida e tanto quanto possível sem barreiras de si próprio e do mundo. O elevado consumo de tabaco e álcool, o contacto com alucinogénios e outros facilitadores de "paraísos artificiais", a banalização do recurso às chamadas drogas leves, em particular o haxixe, e a experimentação mais ou menos continuada de "drogas duras", como a cocaína e a heroína, bem como de substâncias sintéticas, não começam nos meios juvenis dos anos 1960 e estão longe de ser exclusivos da beat generation, dos hippies ou do rock and roll e seus derivados. Mas assumem, desde então, uma expressão própria, quer em dimensão, quer em significado ideológico e cultural.

Por um lado, fazem parte do estilo de vida "subcultural", nos termos de Dick Hebdige (2002 [1979]): a definição de uma identidade grupal e de uma diferenciação face à envolvente social com base na exibição mais ou menos ostensiva de comportamentos, disposições corporais, roupas, adereços e consumos que essa envolvente tende a julgar como problemáticos; e justificando essa exibição por referência a valores ao mesmo tempo hedonistas e subversivos (Hodkinson e Deicke, 2009). Por outro lado, acentuam a dimensão contracultural das representações e práticas juvenis: questionando as formas estabelecidas de conhecer, falar e agir (contrapondo-lhes o potencial heurístico e poiético do uso de substâncias psicoativas, juntamente com outros quadros normativos, como a vida em comunidade ou 
a liberdade sexual); e revertendo os termos e efeitos da classificação social do desvio comportamental (Becker, 1985), afirmando-o positivamente, como um desafio. Finalmente, são um dos eixos narrativos de autorrepresentação do universo cultural do rock, ligando o fulgor e a autenticidade artística às vidas sem limites nem duração, transformando as histórias trágicas de Jimmy Hendrix, Janis Joplin, Jim Morrison, Sid Vicious e tantos outros em "lendas urbanas" (Inglis, 2007), a que os devotados seguidores podiam ir buscar, senão exemplo, inspiração.

Opunk, tal como emergiu no Reino Unido e nos Estados Unidos da segunda metade da década de 1970, em contraponto ao rock então mainstream, e que rapidamente irradiou como grande movimento internacional, filia-se nesta inscrição subcultural e contracultural. Mas acrescenta traços específicos. Primeiro, radicaliza-a, quer na rutura com a indústria musical estabelecida, quer na insistência no lado marginal e subterrâneo, na autoprodução (do-it-yourself) e no viver rápida e intensamente. Segundo, é contemporâneo das duas grandes problematizações do fim do século sobre o sentido das "drogas": a consciencialização dos riscos contidos no consumo descontrolado (postos em evidência pela sucessão de mortes por overdose, desde os anos 70); e a irrupção, nos anos 80, da sida. Terceiro, é um dos terrenos culturais e artísticos onde mais longe se levará a reflexão coletiva sobre aquele sentido, dando origem, nos anos 90, a uma subcorrente, o straight edge, cujo programa é exatamente a libertação pessoal dos abusos, seja do álcool, da droga, do sexo ou, eventualmente, do consumo de carne (cf. Haenfler, 2006).

A situação portuguesa apresenta uma coloração parcialmente própria: a afirmação do punk, nos últimos anos de 70 e sobretudo ao longo da década de 80 , coincide com a sucessão temporal de duas importantes mudanças.

Uma é, na sequência da Revolução de 1974, a escalada no contacto com o mundo das substâncias psicoativas, de um lado mais amplo (sobretudo por causa da chegada de muitos milhares que haviam vivido em África, como colonos ou soldados, mais habituados à presença forte e tolerada de coisas como a marijuana); e, do outro lado, menos subterrâneo (por causa do novo "clima", mais liberal, face a comportamentos anteriormente tidos como desviantes e perigosos). O discurso público tende a substituir a atitude catastrofista adotada pelo Estado Novo por uma abordagem dita mais social, atualizando a estratégia de ação por referência à Europa comunitária e alicerçando-a duplamente, com uma intervenção médico-psicológica orientada para a redução da procura e uma intervenção repressivo-criminal orientada para a redução da oferta (Poiares, 1995; Costa, 1998; Valentim, 2000; Cunha, 2002; Marques, 2008; Agra, 2009). 
A outra mudança ocorre nos circuitos de comercialização e na representação social da economia dos consumos. Ali, com a integração de Portugal nas rotas internacionais e o peso crescente da heroína: algo que poderíamos designar, caricaturando um pouco, como a "chegada" das "drogas duras". Aqui, com a progressiva associação do contacto com as drogas à desestruturação socioterritorial, como produto e indicador de destruição e marginalização de vidas: o foco desloca-se para as realidades da toxicodependência e a figura do junkie, e para o tráfico e a figura do dealer. A "droga" é menos associada a usos recreativos, correntes em meios sociais relativamente favorecidos em capital económico e escolar, e cada vez mais vinculada à experiência subjetiva e às caraterísticas sociais de grupos marginais, famílias desestruturadas, bairros degradados e "problemáticos”, em suma, da periferia urbana. A "questão da droga" estabiliza, portanto, quer nas representações sociais, quer no discurso e na intervenção política, institucional e profissional, sobre um tripé: questão social, ligada às margens, à erosão dos laços sociais e à degradação dos territórios; questão de saúde pública, ligada diretamente aos riscos de consumo excessivo e/ /ou desprotegido e, indiretamente, à propagação de doenças como as hepatites, a tuberculose ou a sida; e questão policial e legal, então enunciada como uma dupla delinquência convergente, do consumidor e do traficante (Chaves, 1999; Cunha, 2002; Dias, 2007; Fernandes e Silva, 2009; Fernandes e Ramos, 2010).

Assim, nos anos 80 do século xx, o punk aparece muito associado a um novo contexto de circulação, consumo e enfrentamento da droga como questão social. Existiu, assim, uma coincidência temporal importante entre fortalecimento das manifestações punk (bandas, concertos, locais de paragem, seguidores, cidades) e adensamento das práticas e representações sociais em torno das drogas, nomeadamente da heroína. E isso foi particularmente evidente nas metrópoles de Lisboa e do Porto, onde as práticas de experimentação e risco das substâncias psicoativas se viram acompanhadas e reforçadas pela omnipresença cultural tradicional do álcool.

\section{Uma questão "da cena"}

Ora, os protagonistas da cena punk portuguesa que entrevistámos para o nosso projeto, ativos nela agora ou nas várias décadas que já a marcaram, de 1977 à atualidade, tematizam a questão do álcool e das drogas como um elemento relevante dessa cena e do seu envolvimento nela. Já vimos que 79\% falam do assunto nos seus depoimentos. Pois centremo-nos neles, que significam 168 dos 214 entrevistados. Primeira pergunta: de quem falam? Quem convocam como sujeitos, quando delimitam os consumos? 
O Quadro 2 mostra como se distribuem as quatro possibilidades: o consumo de álcool e drogas é um assunto de outros definidos em geral, relativamente afastados do sujeito que fala; é assunto de outros que estão próximos, que são da zona, do bairro, da esfera de conhecimento pessoal; é assunto do grupo a que se pertence; ou é mesmo um assunto pessoal, que toca ou tocou diretamente o sujeito como tal.

QUADRO 2 - Consumidores de álcool e drogas, segundo os entrevistados que abordam o tema (em $\%)^{4}$

\begin{tabular}{lr}
\hline Eu: o/a entrevistado/a & 37,5 \\
\hline Nós: o grupo de pares e amigos & 30,4 \\
\hline Os outros da esfera mais próxima, da zona de ação ou conhecimento & 41,7 \\
\hline Os outros da esfera mais afastada, remetidos para o conjunto da cena & 45,8 \\
\hline Sem referência & 1,8 \\
\hline
\end{tabular}

Sobressai a proximidade do tema. Para mais de um terço, o álcool e as drogas são ou foram um assunto seu, pessoal e direto. Para quase um terço, um assunto seu porque do seu grupo. Para dois quintos, um assunto seu porque da sua zona, do seu conhecimento. E, quando procuramos caraterizar o tom geral de abordagem do tema, o que coerentemente predomina é a atitude compreensiva, de quem aceita ou entende o recurso, mais ou menos duradouro, mais ou menos controlado, às substâncias. Tema próximo, "nosso", que há de ter tocado imediata ou obliquamente muitos, senão todos; e em relação ao qual poucos poderão reclamar inocência, o que quer que isso signifique neste caso. Por contraste, é residual a condenação formal de tal prática; e mesmo o lamento pelas consequências negativas (que, como veremos mais à frente, pode ser muito agudo) é estatisticamente pouco frequente. A compreensão é proporcionalmente mais frequente entre os homens, os mais novos e os menos escolarizados (Quadro 3).

A assunção do uso de substâncias psicoativas como questão crítica da cena, assim como a predominância do registo compreensivo na sua abordagem estabelecem bem a diferença com a "droga" como estereótipo e estigma social. Isto é, com um dos elementos, senão o elemento essencial da opinião pública sobre o punk e os punks e da generalidade das reações à sua emergência, nas cidades, ao longo dos anos 80 .

\footnotetext{
${ }^{4}$ A soma das percentagens é superior a 100, porque vários entrevistados indicaram mais do que um tipo de sujeitos.
} 
QUADRO 3 - Tom prevalecente nos depoimentos sobre o consumo de álcool e drogas dos entrevistados que abordam o tema, segundo o género, a idade e o nível de instrução (\% em linha)

\begin{tabular}{|c|c|c|c|c|c|c|}
\hline & & COMPREENSÃO & CONDENAÇÃO & LAMENTO & $\begin{array}{c}\text { NÃO } \\
\text { IDENTIFICÁVEL }\end{array}$ & TOTAL \\
\hline \multirow{2}{*}{ Género } & Feminino & 50,0 & 4,2 & 20,8 & 25,0 & 100 \\
\hline & Masculino & 60,4 & 9,7 & 16,0 & 13,9 & 100 \\
\hline \multirow{3}{*}{ Idade } & $15-30$ & 88,0 & - & - & 12,0 & 100 \\
\hline & $31-45$ & 57,1 & 12,1 & 15,4 & 15,4 & 100 \\
\hline & $>45$ & 48,1 & 7,7 & 26,9 & 17,3 & 100 \\
\hline \multirow{3}{*}{ Instrução } & Básica & 66,7 & 6,7 & 20,0 & 6,7 & 100 \\
\hline & Secundária & 64,1 & 4,7 & 15,6 & 15,6 & 100 \\
\hline & Superior & 53,9 & 12,4 & 16,9 & 16,9 & 100 \\
\hline TOTAL & & 58,9 & 8,9 & 16,7 & 15,5 & 100 \\
\hline
\end{tabular}

Referindo-se a essa década, o entrevistado a que daremos, como a todos os outros, um nome fictício - Leopoldo, com 45 anos feitos no momento da entrevista, morador em Lisboa e programador informático, tendo como habilitações o ensino secundário - sintetiza o que muitos outros assinalaram:

$\mathrm{Na}$ altura, eu acho que aquilo era visto como 'éramos os drogados', 'isto é pessoal da droga'. Eu acho que a grande maioria das pessoas era assim que via. Quando via o pessoal, assim todo junto, a passar na rua, ou qualquer coisa, acho que a generalidade das pessoas tinha é 'isto é droga, estão perdidos. Filhos de Satanás' e coisas do género.

Como todos os estereótipos, este vivia da caricatura, sobrepunha o preconceito ao conhecimento, extrapolava imediatamente do particular para o geral e estendia o atributo, como estigma, a uma classe inteira de indivíduos. A "droga" seria o traço definidor de uma difusa massa de pessoas e formas, como os jovens consumidores de música moderna, as "estrelas" que seguiam e alimentavam, o tempo (a noite) e o espaço (a discoteca, o bar, o festival) que faziam seus. "Droga" e "drogados". Como todos os processos de classificação social, operava por dispositivos de diferenciação e aproximação, o mais forte dos quais foi, por muito tempo (com efeitos 
ainda hoje), a exclusão e até valorização do tabaco e do álcool face às "drogas" propriamente ditas (Carvalho, 2007). A sociologia já descreveu a mecânica social da estigmatização, que, atribuindo e nomeando, constrói e impõe uma categoria negativa e nela reproduz os sujeitos, assim criando a realidade que ostraciza, o desvio que deplora, os outsiders que marginaliza e o pânico moral que gera (Goffman, 1963; Becker, 1985; Cohen, 2002).

Alberto, hoje $e^{5}$ com 46 anos, programador musical no Porto e com o ensino secundário, era, na década de 80, um jovem punk de Torre de Moncorvo. Explica assim porque saiu:

Aquilo começou a ficar muito limitativo para mim. Por outro lado, há sempre a sensação de vingança perante Moncorvo porque era sempre o drogado, era isto e era aquilo. Chegou a hora, viajei muito, nunca me droguei muito e nessa altura não me drogava sequer... Drogo-me mais agora do que me drogava nessa altura. E foi uma chapada de luva branca para muita gente porque eu era um gajo que... Sei lá, uma filha namorar comigo era um terror... Era um gajo considerado maluco.

Outras ilustrações claras da lógica do estereótipo e do estigma podem ser encontradas na elisão do que, na oposição do punk à cultura bippie e rock mainstream, levou ao próprio questionamento dos psicotrópicos, ou do surgimento, nos anos 90, no seu interior, da bandeira straight edge de uma vida livre de dependências.

Seria, todavia, um erro grosseiro reduzir a "droga" à esfera das representações e classificações sociais. O uso para experimentação, recreio ou reforço energético de substâncias psicoativas, assim como a sua celebração como atributo e sinal de liberdade e provocação, e o correlativo risco da dependência, de ficar "agarrado" ao álcool ou à droga, fazem parte integrante do universo artístico, cultural e comportamental do punk, como de outras variantes e decorrências da música pop, rock e eletrónica (cf. Carvalho, 2007). ${ }^{6}$

Várias canções assinaladas pelos entrevistados como referenciais na cena punk portuguesa exprimem-no bem. Podem fazê-lo no registo satírico,

\footnotetext{
5 Por facilidade de expressão, usaremos os advérbios "hoje" ou "agora" para referir as idades que os entrevistados tinham no momento em que foram entrevistados.

${ }^{6}$ Em 1997, um fanzine significativamente intitulado Kannabizine colocava sistematicamente uma questão aos seus entrevistados, sobre o consumo das drogas e a sua liberalização. O tema é também recorrente noutros fanzines. Retirados os que se filiam na corrente straight edge, o tom geral é de simpatia para com a liberalização das "drogas leves" e a inscrição do seu consumo no quadro das opções individuais de vida.
} 
de que é ilustração bastante, mas longe de única, o hino ao álcool concebido na forma de um credo pelos Peste \& Sida: ${ }^{7}$

Creio no álcool, poderoso criador da formidável carraspana

Creio na aguardente, sua filha concebida por graça do alambique

Nasceu da puríssima cana derramada e sedimentada sobre um casco

E surgiu ao terceiro dia graciosa e triunfante na garrafa

Garrafas destas hão-de vir a nossas casas alegrar farras sem fim

E dar descanso a pobres, ricos, novos, velhos, sejam santos ou diabos

Ou podem fazê-lo no registo proclamatório, do desafio assumido e enunciado, de quem vê nesse uso do que a ordem social teme e repudia como ilícito e perigoso mais um recurso para fugir à norma e passar os limites. Uma banda próxima da cena punk, e cuja influência sobre esta é reconhecida por alguns dos nossos entrevistados, os Stratus, di-lo com clareza, na canção Um chuto no quarto, de 1982:

Caveiras, drogas e correntes

Fica tudo na maior

Vive a vida diferente

Não queiras ganhar bolor

Fumando o teu cachimbo preto

Vai tudo às nuvens e tu também

Estás num mundo obsoleto

Também és um filho da mãe

Um chuto no quarto

Parto logo o penico

Subo para o palco

Bem speedado.

O consumo partilhado de substâncias psicoativas, capazes de provocar alterações de perceção, consciência, humor e energia, suspendendo ou invertendo temporariamente a ordem das coisas e sacudindo as convenções, pode ser praticado e representado como componente essencial da sociabilidade

7 Da canção Carraspana, de 1987. Ver também, sobre as drogas e no mesmo registo, As histórias da minha avó, de 1996, dos Kú de Judas. 
grupal de natureza hedonista - pela "curtição". Na sua canção de 1999, Festa tribal, os Mata-Ratos evocam bem a atmosfera:

Ouve-se ao longe
O rufar dos tambores
A noite chama-nos
Para a festa selvagem
Acendem as chamas
Aparecem calores
A dança do sexo
No rufar dos tambores

Sou um animal

$\mathrm{Na}$ festa tribal

Ouve-se ao longe

O rufar dos tambores

A noite chama-nos

Para a festa selvagem

Escorre o álcool

Esquecem-se os dias

Nas veias no sangue

Elevam-se as iras

Sou um animal

$\mathrm{Na}$ festa tribal

Esta presença do álcool e das drogas no centro da cena punk é corroborada pelos depoimentos dos entrevistados a propósito da sua própria experiência de consumo. A cerveja e o vinho, no que toca ao álcool, a heroína e o cannabis, os speeds e a cocaína, no que respeita às drogas, são as substâncias mais correntes, pelo menos a avaliar pelas referências feitas pelos 168 entrevistados que abordam o assunto (Quadro 4).

Não se apresenta sem problemas a indagação sobre o consumo de álcool e drogas. Os investigadores devem estar atentos a duas situações que podem alterar significativamente a qualidade da informação recolhida por entrevista: o respondente considera embaraçosa uma pergunta direta sobre consumos de substâncias que são objeto de censura moral ou proibição legal 
e evita-a, ou esconde ou relativiza um comportamento "desviante"; ou, pelo contrário, exagera, por afirmação pessoal, provocação ou conformidade com um certo papel "marginal" ou disruptivo associado à cena a que se sente vinculado. $\mathrm{O}$ guião da entrevista não continha nenhuma pergunta pessoal e direta, mas incentivava à reflexão sobre a questão, procurando depois os investigadores identificar, nessa reflexão, possíveis informações sobre consumos.

$$
\begin{gathered}
\text { QUADRO } 4 \text { - Tipos de álcool e drogas referidos pelos entrevistados } \\
\text { que abordam o tema }(\mathrm{em} \%)^{8}
\end{gathered}
$$

\begin{tabular}{lclc}
\hline TIPOS DE ÁlCOOL & $\begin{array}{c}\text { \% DE ENTREVISTADOS } \\
\text { QUE OS REFEREM }\end{array}$ & \multicolumn{1}{c}{ TIPOS DE DROGAS } & $\begin{array}{c}\text { \% DE } \\
\text { ENTREVISTADOS } \\
\text { QUE OS REFEREM }\end{array}$ \\
\hline Cerveja & 13,1 & Heroína ("cavalo") & 28,6 \\
\hline Vinho & 6,6 & $\begin{array}{l}\text { Cannabis } \\
\text { ("haxixe"/"ganza", } \\
\text { "marijuana"/"erva") }\end{array}$ & 25,0 \\
\hline Aguardente & 1,8 & Speeds (dinintel) & 18,5 \\
\hline Whiskey & 1,8 & Cocaína & 10,1 \\
\hline Cachaça & 1,2 & Cola & 4,8 \\
\hline Gin & 1,2 & $\begin{array}{l}\text { Calmantes ("drunfos", } \\
\text { rohypnol) }\end{array}$ & 3,6 \\
\hline Misturas & 1,2 & Ácidos & 3,0 \\
\hline Vodca & 1,2 & Ecstasy (MDMA) & 1,8 \\
\hline
\end{tabular}

Tendo isto em mente, vale a pena olhar para os Quadros 5 e 6, que sistematizam essas informações. A partir do primeiro, verificar-se-á que, em $55 \%$ dos 168 entrevistados que abordam o tema do álcool e das drogas, é possível sondar a existência ou não de consumo de álcool; o mesmo se passa, em relação às drogas, com $58 \%$. Ora, em cada um dos subgrupos assim constituídos, a larguíssima maioria dos respondentes assume o consumo (presente e/ /ou passado) de ambos os tipos, em proporções que chegam quase aos quatros quintos para o álcool e quase aos dois terços para as drogas.

${ }_{8}^{8} \mathrm{O} / \mathrm{a}$ entrevistado/a poderia referir mais do que um tipo. 
QUADRO 5 - Assunção do consumo de álcool e drogas pelos entrevistados que abordam o tema

\begin{tabular}{|c|c|c|c|c|c|c|}
\hline & \multicolumn{3}{|c|}{ CONSUMO DE ÁLCOOL } & \multicolumn{3}{|c|}{ CONSUMO DE DROGAS } \\
\hline & N. ${ }^{\circ}$ & $\begin{array}{c}\% \\
\text { sobre } 168\end{array}$ & $\begin{array}{c}\% \\
\text { sobre } 92\end{array}$ & $N .^{\circ}$ & $\begin{array}{c}\% \\
\text { sobre } 168\end{array}$ & $\begin{array}{c}\% \\
\text { sobre } 97\end{array}$ \\
\hline Consome/iu & 72 & 42,9 & 78,3 & 63 & 37,5 & 64,9 \\
\hline $\begin{array}{l}\text { Não } \\
\text { consome/iu }\end{array}$ & 20 & 11,9 & 21,7 & 34 & 20,2 & 35,1 \\
\hline $\begin{array}{l}\text { Sem } \\
\text { informação }\end{array}$ & 76 & 45,2 & \multirow[t]{2}{*}{100} & 71 & 42,3 & \multirow[t]{2}{*}{100} \\
\hline TOTAL & 168 & 100 & & 168 & 100 & \\
\hline
\end{tabular}

Por sua vez, o Quadro 6 apresenta as combinações de consumos, mostrando que o padrão mais habitual é a acumulação de álcool e drogas - um padrão que, aliás, carateriza 43 do total de 168 respondentes, quer dizer, um em cada quatro.

QUADRO 6 - Assunção de combinações de consumo de álcool e drogas pelos entrevistados que abordam o tema ( $\%$ em coluna)

\begin{tabular}{|c|c|c|c|c|c|}
\hline \multirow[t]{2}{*}{ ÁLCOOL } & \multicolumn{5}{|c|}{ DROGAS } \\
\hline & Consome/iu & Não consome/iu & Sem dados & Total & (N) \\
\hline Consome/iu & 68,3 & 32,4 & 25,4 & 42,9 & (72) \\
\hline Não consome/iu & - & 47,1 & 5,6 & 11,9 & (20) \\
\hline Sem dados & 31,8 & 20,6 & 69,0 & 45,2 & (76) \\
\hline Total & 100 & 100 & 100 & 100 & \\
\hline (N) & (63) & (34) & (71) & (168) & (168) \\
\hline
\end{tabular}

Outro dado assinalável é a frequência com que os entrevistados assumem a regularidade do consumo. 40 dos 97 entrevistados sobre os quais dispomos de informação quanto ao consumo de drogas assumem que o fazem ou fizeram regularmente, o que representa $41 \%$, mais de dois quintos ( $17 \%$ dizem que o consumo é ou era ocasional, e os restantes ou não se referem ao consumo ou não se referem à sua frequência). 40 dos 92 entrevistados sobre os quais dispomos de informação quanto ao consumo de álcool assumem que o fazem ou fizeram regularmente, o que representa $43 \%$, $13 \%$ dizendo que o fazem ou fizeram só ocasionalmente. E, finalmente, 
quando ventilámos os depoimentos sobre consumos por género, idade e nível de instrução, o dado que mais sobressaiu foram os $100 \%$ de maiores de 45 anos acerca dos quais dispomos de informação que declararam consumir ou ter consumido drogas e/ou álcool.

\section{Consumos}

Sumariemos: a) as drogas não são um elemento exclusivo da cena punk, nem sequer é a intensidade da sua presença que distingue estas de outras (sub)culturas juvenis contemporâneas; b) não obstante, constituem um ingrediente básico da constituição e da representação da cena, aos olhos dos seus protagonistas; e portanto c) a "droga", reenviando certamente para um estereótipo social, conota também uma prática efetiva de consumo e uma abordagem crítica, quer no plano criativo, quer no estilo de vida.

As entrevistas, realizadas no quadro de uma investigação sociológica, foram motivo para que muitos protagonistas, ativos ou retirados, procedessem, em interação com um/a estranho/a à escuta, à reconstrução e reapreciação reflexiva do seu próprio percurso, pessoal, geracional e grupal e da sua própria experiência, passada e presente. Os discursos dos atores do punk português são, aliás, incontornáveis para a plena compreensão da sua emergência, dinâmica e impacto.

Os consumos de substâncias psicoativas foram logicamente um dos tópicos dessa reflexão e reinterpretação que fizeram cruzar histórias pessoais e coletivas. Porque é que o recurso a álcool e drogas se tornou tão banal e foi vivido com tanta paixão pelos geralmente jovens cultores do punk e, em muitos casos, acabou por acompanhar o seu crescimento e definir um traço persistente da sua visão e comportamento no mundo? Porque se tornou, não só um motivo artístico e cultural - um tópico de que falar, na música, nos concertos, nos fanzines, nos grupos - como também um ingrediente, às vezes indispensável, dos modos de ser e agir?

Os entrevistados falam abundantemente sobre isto e seria fastidioso reproduzir aqui todas as falas. Mas podemos identificar os argumentos principais, que rodam em torno de um ou vários eixos.

O primeiro é o contexto de socialização, primária, na família, mas sobretudo secundária, no grupo de pares e, em particular, no ambiente de diversão urbana e noturna. Teresa, uma designer de Lisboa agora com 49 anos, enfatiza muito aquele aspeto: "A minha mãe tinha amigos que davam na erva, amigos!". Eurico, comprador de moda, 42 anos, lembra: "Toda a gente sabia que a droga fazia parte da noite". Podia ser o preço da integração no grupo, como diz Samuel, 47 anos, cameraman: "se não consumisses drogas 
os grupos não se abriam; havia um grupo de pessoas, se querias entrar no grupo ou davas nela ou não entravas".

O segundo eixo acentua a acessibilidade das drogas: primeiro, das drogas ditas leves, em particular nos anos 70 e com destaque, como já vimos, para o período subsequente à revolução democrática; depois, com a progressiva integração de Portugal nos circuitos internacionais de tráfico, o acesso à heroína. A conjuntura de emergência do punk é marcada por estas duas novas acessibilidades, assim como pela transformação, que também ficou atrás descrita, da economia moral das "drogas". Vários entrevistados ligam esta "facilidade de acesso" à inconsciência dos efeitos nocivos do abuso, ou a sua romantização com as "lendas urbanas" de que fala Inglis (2007), as histórias heroicas e trágicas de ícones como Morrison ou Sid Vicious. Note-se a propósito que, quando aqueles que tematizam a centralidade do álcool e das drogas na cena punk nacional procuram situar temporalmente a conjuntura em que ela foi mais intensa ou visível, distribuem equilibradamente a influência do álcool pelas décadas de 1980 a 2000, mas tendem a concentrar as drogas sobretudo nos anos 80 (Quadro 7).

QUADRO 7 - As conjunturas em que foi mais determinante o consumo de álcool e drogas na cena punk portuguesa, segundo os entrevistados que abordam o tema $(\mathrm{em} \%)^{9}$

\begin{tabular}{lcc}
\hline CONJUNTURAS & CONSUMO DE ÁLCOOL & CONSUMO DE DROGAS \\
\hline Anos 70 & 4,8 & 5,7 \\
\hline Anos 80 & 32,7 & 39,6 \\
\hline Anos 90 & 33,9 & 32,8 \\
\hline Anos 2000 & 28,6 & 21,9 \\
\hline
\end{tabular}

O já citado Eurico, agora com 42 anos, sintetiza bem o argumento da acessibilidade:

Quer dizer, está ao virar da esquina não é? E num grupo de amigos é muito fácil o comportamento ser idêntico para todos, passar de uns para outros por fazer parte de círculos. [...] Em Portugal muito antes do que as pessoas querem admitir, no contexto da Guerra Colonial já existia e de que maneira, a partir dos anos 60 e

\footnotetext{
${ }_{9}$ Os entrevistados poderiam indicar mais do que uma conjuntura.
} 
dos anos 70 sempre teve uma presença de alguma maneira evidente nas discotecas e nas boites. Quem frequentava as discotecas - e a parte violenta e dura da noite acabava por conviver com ela de alguma forma. Era uma questão de oferecer ou de querer experimentar sem saber muito bem que consequências é que mais tarde poderiam aparecer. A informação era quase nenhuma. Para quem apanhou esse início logo a seguir à Revolução e um contexto muito duro - muito deprimido socialmente com um país muito a braços com uma crise económica. [...] E essa ausência de informação era propícia a tudo porque ninguém imaginava que o amigo do lado pudesse morrer de uma overdose com a mesma facilidade que, enfim, acontecia lá fora.

O terceiro eixo de argumentação salienta os efeitos das substâncias psicoativas sobre a energia das pessoas. O "subo para o palco/ bem speedado", da canção dos Stratus que já citámos, quer dizer, o uso de estimulantes da atenção, da vigília e da resistência física, não só para as performances das bandas como para a ação dos públicos nos concertos - e que também pode ter que ver, como está bem documentado, com períodos de maior exigência, nos estudos ou no trabalho. Estímulo, incentivo: recreação, energia, performance, estudo e trabalho. "Não se faz festa [quer dizer, animação, ruído e movimento] com garrafas de água nem com saladas", diz o jovem Gonçalo, de Viana do Castelo, um web designer de 26 anos. E a lisboeta Verónica, agora com 55 anos, licenciada, filósofa, astróloga e música, vai buscar o exemplo dos Romanos, que "tomavam o veneno aos bocadinhos para o caso de serem envenenados não morrerem”, para fazer a defesa do uso controlado de psicotrópicos, porque potenciam a liberdade e a autonomia pessoal. Nos anos 80, concede, muitos não conseguiram "ir ao submundo e voltar”. Mas:

Quem dá a volta e vive é porque tem uma capacidade de transmutar os efeitos secundários dos venenos. E isso significa que são lombas, no sentido benéfico, mobilizadoras da evolução das pessoas, dos seres e das coisas. Não é à toa que algumas pessoas, nas quais eu me incluo sem pudor absolutamente algum, que vêm desde aí, são altíssimos mobilizadores da liberdade de espírito e da assunção do poder pessoal, da abertura de horizontes, da utilização de alternativas e etc. para outras gerações que, se calhar, não tendo sido sujeitas a esse grau tão intenso de contraste, não tiveram se calhar a tarimba do que é que são os grandes saltos. Digamos, nós somos peritos em grandes saltos. E altas centrais de transmutação das trevas em luz, e essas coisas todas. Portanto, sim, foi uma enorme escola, como as escolas iniciáticas.

O quarto eixo de argumentação, estando próximo deste terceiro, coloca porém o foco na cultura da experimentação. As drogas deveriam ser 
enquadradas no processo de descoberta, assimilação da novidade, pulsão do risco, e também desafio às regras convencionais e às gerações mais velhas. Um processo relativamente comum na adolescência e na transição para a vida adulta, inscrevendo-se na lógica de moratória social, suspensão do destino e adiamento das escolhas, inerente à juventude nas sociedades modernas - e que o rock teria levado a um grau superior de expressão. "Sim, experimentámos", sentencia Damásio, 39 anos, agora chefe de cozinha em Londres. "O punk rock é liberdade, liberdade total", recorda Emanuel, 41 anos, motorista; "é para quebrar regras, estás a ver?", proclama Alberto, 46 anos. "Um gajo quando é novo sente-se um bocado indestrutível" - e quase conseguimos sentir a nostalgia destas palavras de Samuel, 47 anos, como nas do mesmo Alberto: "Vivia-se muito no sonho".

Finalmente, o quinto eixo de argumentação é o que lida com a dependência, distinguindo-a explícita ou implicitamente do uso recreativo e/ou esporádico, ou do contacto experimental e mais ou menos ritual, iniciático, para o crescimento pessoal, a integração tribal e o conhecimento do mundo. Nos seus termos, o álcool e as drogas tornam-se parte de uma encruzilhada existencial (que é um dos temas fundamentais da criação punk, cf. Silva e Guerra, 2015), a condição sine qua non para manter um nível mínimo de contacto social ("não consigo lidar com as pessoas sóbrio a partir de uma certa hora da noite", confessa Alberto), ou para gerir consigo próprio ou no seu grupo um estado de desesperança, descrença, desespero. Não surpreenderá que esse seja tópico recorrente nas canções, várias das quais fazem da dependência do álcool e das "drogas" um epítome das encruzilhadas existenciais em que os sujeitos se encontram.

A canção Já estou farto, dos Kú de Judas, que um em cada nove dos entrevistados do projeto KISMIF considera uma das 10 mais influentes na cena punk portuguesa, di-lo cristalinamente:

\section{Já estou farto}

Com um copo de vinho

E um charro na mão

Ainda tem um bocadinho

Ainda tem a solução

Já estou farto

O mesmo álbum As vozes da raiva, de 1996, inclui outra canção de impasse e desespero. E mais uma vez aparece a "droga", como ingrediente básico de tal estado: 
Passo os dias desesperado

Nesta terra imunda e porca

Quero sair por qualquer lado

Mas ninguém me abre a porta

\section{Sniff, sniff bostik}

Sinto o corpo todo a ferver

Tudo explode dentro de mim

Sinto a cabeça a derreter

Tenho que ir até ao fim

Toda a noite a flashar à toa

Sem saber para onde ir

Pelas ruas de Lisboa

Todo roto e a cair.

11 anos depois, em 2007, os Motornoise lançam a canção Podre de bêbedo. O tema é o mesmo: a dependência é um círculo vicioso, causa e efeito, assim como sintoma, de uma condição problemática, que será preciso, mas tão difícil, romper: "Mais uma noite, igual a tantas outras/ Perdi-me, droguei-me, embebedei-me outra vez [...]".

\section{Drogas e drogas}

A história que o punk português conta acerca de si próprio - nas canções, nos fanzines, nos depoimentos dos protagonistas - é de uma cena "fora dos trilhos" (Silva e Guerra, 2015), nas margens da sociedade e da indústria musical e contrapondo-lhes uma ética e um fazer artístico baseados na autoprodução (do-it-yourself) e no constante desafio às instituições. O "excesso" cabe bem nessa história. A linguagem direta, grosseira, a excentricidade ostensivamente afirmada no espaço público, pelas roupas, adereços, cabelos e incisões corporais, a mensagem radical, particularmente dura com políticos, militares e polícias, além de religiosos e patrões, e a promessa de convulsões e anarquias, tudo isso faz valer, ideológica e artisticamente, o excesso, o que transborda, porque o mainstream social e musical não consegue domesticá-lo. A “droga”, como estereótipo estruturante da representação deste potencial de "desvio" encarnado nos jovens punks, como estigma social transformado pelo punk em seu recurso identitário, contracultural; e as "drogas", o álcool e as substâncias psicoativas ilegais, como componentes e indutores de experiências de superação dos 
limites, como fautores de "universos paralelos" e "paraísos artificiais", como estimulantes energéticos, cognitivos e poiéticos e emblemas tribais e geracionais - encaixam logicamente nesse "excesso", que potenciam. Como resume Camila, agora com 44 anos, dona de uma loja de roupa em Lisboa e com o ensino secundário, "a droga, o álcool, o excesso, acho que o excesso faz parte de tudo isso".

"Faz parte" por causa desse seu quadro normativo e ideológico; mas também em virtude da configuração propriamente artística e cultural - pela aceleração e a intensificação que esta exige, "tocar alto e viver depressa", comprimindo o tempo, numa vertigem de música e consumos. O circuito underground - a formação da banda, a gravação das demos, os concertos dados ou assistidos, os círculos de fãs, as lojas de roupas, discos e adereços, etc. - multiplica a escala em que o acesso se torna mais fácil e necessário, até para combater o cansaço e aumentar episodicamente a capacidade física.

Por conseguinte, o ponto crítico não é bem o uso de drogas, mas sim de que drogas e de que forma, com que intensidade. Norberto, que, acabada a licenciatura, trabalha no Porto em conservação e restauro, enuncia, aos 45 anos, com clareza a questão, a partir da perspetiva dominante na cena, aquela que, como já vimos, prefere compreender a condenar o envolvimento maciço nas drogas:

A heroína é anti punk. Completamente. Agora, tudo o resto... Agora, acho que a droga faz parte destes movimentos... Punk sem speed não tinha sido o que é... Não só não lhes chegava a energia toda que eles tinham, ainda tinham que mamar mais um bocado... Mas acho que faz parte, e acho que faz parte da natureza do homem procurar coisas que te retirem um bocado da realidade. Todas as sociedades o têm e vão ter. Por isso, uma sociedade sem substâncias psicotrópicas não existe.

No universo dos nossos entrevistados, esta é a verdadeira questão. Não o álcool, não o tabaco, não o haxixe ou a marijuana, mas sim a heroína, o "cavalo" que "agarra", que leva à dependência e destrói. Neste ponto reproduzem - como acontece noutras cenas juvenis, por exemplo no transe psicadélico (Carvalho, 2007) - o estereótipo social que faz do tipo de substância consumida o ponto crítico do consumo. "Drogas para uso recreacional [sic] até ok; toxicodependência não", resume Miguel, o editor de música lisboeta, com 37 anos de idade.

Para muitos, a história da década de 1980 é a da progressão da heroína e dos seus efeitos devastadores. E vários dos que, estando hoje nos 40-50 anos, conheceram por dentro essa década, não poupam nas palavras. "Depois entrou a coisa da heroína, começou a haver problemas com droga, os punks 
começaram a agarrar-se todos à droga, como costuma ser" (Frederico, 49 anos, tradutor); "na altura não sabiam, passavam de uns para os outros, passado um tempo um grupinho já estava perdido [...]; foi tipo tábua rasa" (Joana, 49 anos, artista plástica); "começaram a acontecer coisas más, começaram a desaparecer amigos nossos, começaram a falecer e as coisas começaram a correr mesmo mal" (Virgínia, 48 anos, atriz e professora); "em meados dos anos 80 , finais... começa-se a ver mais desgraça nesse aspeto, muitos a perderem-se, overdoses, muitos com problemas devido à droga, como roubarem, entrarem por esses caminhos, a serem presos, a apanharem SIDA" (Gabriel, 42 anos, professor); "montes dos nossos melhores foram-se com a heroína" (Gusmão, 50 anos, pequeno empresário); "a partir de meados dos anos 80 até aos 90, tive amigos a morrer todas as semanas com drogas duras" (Álvaro, 56 anos, músico e compositor).

A penetração das tais drogas duras, o percurso que, começando nas drogas ditas leves e no uso recreativo pode conduzir ao consumo incontrolado e desprotegido e à dependência, os múltiplos efeitos possíveis, desde as debilidades físicas permanentes e a vulnerabilidade à hepatite ou à sida até à morte por overdose, suicídio ou doença, desde a desintegração grupal e o isolamento pessoal até aos comportamentos antissociais e à delinquência, tudo isso coloca radicalmente em questão a coesão e sobrevivência da cena punk. Alguns testemunhos autobiográficos são bastante impressionantes. Ouça-se, por exemplo, Fausto, o web designer que tem agora 43 anos:

Começa-se sempre pelos charros. No meu caso, foi muito rápido para a drunfaria [sic], depois snifar cola, e depois vêm as drogas todas, especialmente a heroína. E aí há um fascínio, quando se é muito puto. Os pais enchem-nos a cabeça com aquelas histórias do terror, que as pessoas morrem e isso tudo e há o fascínio pelo perigo. E o punk tem muitas histórias, a começar por aquele puto estúpido, o Sid Vicious. Muitos deles estão mortos, muitos deles estão com SIDA... Em 1990, um ano marcante para mim, morreram 20 e tal amigos de overdose. [...] As pessoas até olham e dizem 'ah, estás porreiro, mais ou menos funcional' mas estamos todos lixados! Eu incluo-me nesse grupo, estamos todos lixados da cabeça! Não é nada fácil, estamos com muitas brancas, cheios de paranoias e frustrações. Perdemos anos e anos da nossa vida!

E Valentino, de 45 anos, vivendo agora, como tradutor, na Alemanha:

Chegou uma altura em que eu me tornei num criminoso. Tornei-me exatamente naquilo que nunca queria ser. Mas pronto, já paguei a minha divida à sociedade. Até assaltos à mão armada fiz, chavalo. Mas andava completamente perdido. Já não era eu, já era outra pessoa transformada. Só que depois não era só o cavalo. Era cavalo, 
eram drunfos, era álcool, eram misturas. Tu estavas completamente noutro mundo, estás a ver? Completamente perdido, até a minha família roubei. Tu imagina, se até à tua própria família perdes o respeito e roubas, imagina o que é que não fazes aos outros. Só na Portela roubei meio mundo. [...]. Mais tarde, depois, passei-me completamente, o meu velho sendo militar tinha uma coleção de armas grande, peguei numa das armas [...]. Usei a arma muitas vezes mas nunca meti balas na arma porque mais ou menos sabia de antemão que se tu usas uma arma é muito simples acabares com a vida de alguém. E isso eu nunca estive preparado para fazer. [...] Portanto ainda havia um resíduo cá, no subconsciente de, vá lá, sabes que andavas a fazer mal mas não querias o mal total.

Logo em 1979, na canção Jorge morreu (que cinco dos nossos entrevistados considerarão ser das mais influentes na cena punk nacional), os UHF cantam o fim trágico de um amigo, que, "como tu e eu", "andava por aí, queimando o cigarro, queimando os nervos". A referência era indireta, mas suficientemente explícita, como se pode ver pela sequência dos versos (e como nos confirmou, em entrevista, um dos membros da banda):

Ele andava por aí

Como tu e eu andamos

Queimando o cigarro

Queimando os nervos

Nevoeiro no cérebro

Num bailado de fantasmas

Entre o frio e zelo

E a importância dos notáveis

Jorge morreu

Jorge morreu

Ele tinha a tua cara

Ele tinha a minha cara

Ele era ninguém

Que a vida desafiava

Jorge um dia passou

À frente da ventania

Entoando o refrão

E uma velha melodia 
Jorge morreu

Jorge morreu

Onde estás, onde estás?

Quem te matou, quem te matou?

Deixou a cidade

Subiu à montanha

Entrando na paisagem

Onde um homem se amanha

Jorge parou

Os ponteiros da vida

Mergulhando os olhos

No mar de água fria

Jorge morreu

Jorge morreu

Várias bandas darão subsequentemente o passo lógico de incorporar a "droga" e o seu tráfico como um dos alvos críticos. Os Vómito veem aí os mecanismos de reprodução da exclusão social (Putos da rua, 1988):

Vivem em bairros bastante degradados

Só miúdos pobres e mal alimentados

Que futuro será o da nossa sociedade?

Há putos com fome vagueando pela cidade

Putos da rua que vendem cola

Putos da rua que não vão à escola

Quando crescem tornam-se

Vagabundos e ladrões

Passam as suas vidas

Dentro e fora das prisões

Todos os tratam

Com agressividade

Nunca mais vão ter

Um dia de liberdade 
Putos da rua que vendem cola

Putos da rua que não vão à escola.

Um ano depois, no seu registo desconstrutivista, os Peste \& Sida cantarão Chuta cavalo, uma história de vida típica de bairro problemático, que acaba mal:

Está de volta ao bairro

No meio da loucura

Já anda nas ruas à procura de aventura

Vestiu-se de lavadinho e foi a casa da avó

Porque tinha saudades, saudades do pó.

Já tentou matá-la, afogá-la numa pinga

Empenhou as pratas e comprou uma seringa

Já tem o panfleto, custou-lhe uma milena

Foi para casa dar um caldo mais a sua pequena.

Chuta cavalo, chuta cavalo, chuta cavalo, chuta!

Chuta cavalo, chuta cavalo, chuta cavalo e morrerás

Oé, oé, oé, oó.

Esta é uma história do bairro onde vivo

Há não sei quantos anos era divertido

Agora partiram cada um para seu lado

Foram à procura daquele pó danado

Uns foram na Famel às partes [?] para o estica

Roubaram duas velhas lá para as portas de Benfica

Com o horror no rosto no WC deitados

Mesmo à beira da morte para mal dos seus pecados.

Chuta cavalo, chuta cavalo, chuta cavalo, chuta!

Chuta cavalo, chuta cavalo, chuta cavalo e morrerás

Oé, oé, oé, oó.

E, em 1999, os Trinta e Um lançam o álbum O cavalo mata (um dos 10 mais influentes na cena, para um décimo dos nossos entrevistados), cuja canção homónima lamenta uma overdose fatal:

Uma gringa espetada na veia

Numa escada à chuva deitado no chão 
Foi assim que te encontraram

Morto na rua pela droga, irmão.

O cavalo roubou-te a vida

E a mim um grande amigo

E não há nada que eu possa fazer

Para voltar a estar contigo.

Uma overdose foi o teu fim

Sempre disseste que ia ser assim

Julgava que falavas da boca para fora

Até chegar essa maldita hora

O cavalo mata!

\section{Múltiplas narrativas}

O sentido, a intensidade e os efeitos do recurso a substâncias psicoativas constituem um tópico maior das representações que os protagonistas da cena punk portuguesa fazem sobre ela e os seus percursos nela. Este tópico aproxima-os uns dos outros, por várias razões: o estereótipo que os associa à droga porque suspeitos de comportamentos "desviantes" e assim os estigmatiza; a centralidade do tema na história da música moderna e, em particular, no grande tronco do rock e suas ramificações; a aura projetada sobre o meio artístico, a desenvoltura boémia que ele cultiva e a experimentação transgressiva que ostenta; o simbolismo disruptivo, como um dos mais radicais desafios ao consenso normativo; e a ligação emblemática à fisicalidade da criação e do estilo de vida apreciados na cena punk, com o seu caraterístico enfoque no corpo, na performance e no encontro multitudinário e festivo dos corpos.

Entretanto, a história das drogas na cultura musical juvenil é isso mesmo, uma história. Ela começou por questionar classificações longamente estabelecidas, designadamente as que remetiam para a esfera lícita e até grandiosa do tabaco e do álcool, e excluíam como perigosas e interditas outras substâncias de efeitos não muito diversos, como o haxixe, ou toleravam em certos meios e tempos específicos (como as diversões ocasionais em círculos abastados) o que execravam no espaço público, nos jovens e nas classes e territórios "problemáticos". Ela celebrou poeticamente as promessas de libertação e realização pessoal, de novas experiências sensoriais e cognitivas, de superação do real através de "paraísos artificiais", associadas à experimentação de drogas. Ela avançou por interseções crescentes com a expansão 
do tráfico internacional de drogas ilícitas muito lucrativas e a intensificação do consumo de substâncias como a heroína e dos padrões de habituação e dependência. Ela viu-se confrontada com os factos pesados da degradação física e relacional, dos excessos e suas consequências, das overdoses, das tuberculoses, hepatites e sida, ao mesmo tempo que sujeita a uma reação política, judicial e médica oscilando entre a estigmatização e a perseguição, de um lado, e o tratamento e redução de danos, do outro.

Os protagonistas da cena punk participam nesta história. Contam a sua própria história, de que um dos eixos narrativos principais é a diferenciação geracional. Os anos 80 teriam sido marcados pela desestruturação causada pela heroína e as misturas, e os anos 90 pela travagem dos consumos mais perigosos e até pela generalização do medo ("a minha geração, diz Vasco, agora com 37 anos, tinha medo das drogas, de ver a heroína e íamos ver os exemplos dos anos 80"). Atualmente, a cena combinaria os habituais e, mais do que tolerados, celebrados excessos alcoólicos e estaria consciente do próximo desenvolvimento legislativo - depois da descriminalização do consumo e da posse para consumo de drogas ilícitas, ocorrida em 2001, a futura legalização do comércio de haxixe e substâncias afins. Mas manifestaria maior distância do que no passado perante os consumos "pesados"; como sumaria Luís, estudante, com 32 anos, "há menos toxicómanos de drogas pesadas nos movimentos juvenis do que havia antigamente, mas há mais álcool e drogas leves".

Outro poderoso eixo narrativo contrapõe, para lá de gerações, correntes ou subcenas, quer dizer, diferentes maneiras de interpretar e praticar o punk. A partir dos anos 90, o straight edge desenvolverá um discurso e estilo de vida radicalmente contraposto aos abusos (de álcool, droga e sexo ocasional), precisamente em nome dos valores de autonomia e liberdade pessoal do punk. Esta posição foi e continua a ser alvo de enorme controvérsia no interior da cena. Mas, mesmo sem chegar a tão drástica atitude, vários outros protagonistas fazem ponto de honra em não deixar reduzir o rock ao seu próprio estereótipo ("Se o lema é 'sexo, drogas e rock ' $n$ ' roll', então o hardcore não é para ti”, diz Raquel, 32 anos) e em criticar, em nome do punk, essoutra forma de alienação e resignação que é a dependência (como conclui Damásio, 39 anos, "se te tornares um junkie tornas-te mais um que caiu no sistema").

A história das "drogas" no punk não está, pois, concluída. A presença passada e presente, a influência da presença passada sobre o presente e os modos de relação que, seguindo, modulando ou rompendo com o passado, se cruzam neste presente, constituem uma dinâmica social em curso, que não pode ser dada por adquirida nem pode ser descrita a um só traço ou cor. 
É um problema, no sentido de uma questão por resolver, que existe e que interpela. Com o ângulo de observação que privilegiámos neste artigo, e a informação que ele permitiu obter, não tivemos a pretensão de contribuir para o inventário analítico das práticas de consumo de álcool e drogas, na cena portuguesa. Não era esse o objetivo, não se orientava para aí o dispositivo metodológico. Mas julgamos ter ajudado a compreender três pontos críticos: a) a natureza problemática da relação com as drogas nessa cena, seja do ponto de vista dos seus valores, normas e crenças, seja do ponto de vista dos seus estilos de vida, seja do ponto de vista da sua criação artística; b) a centralidade da enunciação e abordagem desta questão, como questão identitária, isto é, respeitante ao nome, à coesão e ao posicionamento da cena; e c) a diversidade das atitudes e discursos que nela circulam e se confrontam, confrontando-se todos ao mesmo tempo com a envolvente societal, a seu propósito.

Se o presente artigo pudesse afastar representações demasiado ligeiras e uniformes, próximas por aí dos estereótipos correntes mesmo quando produzidas em campos disciplinares especializados, e pudesse incentivar abordagens mais atentas às experiências dos atores, às palavras reflexivas dos atores sobre a suas experiências e à diversidade de atores, experiências e discursos, então teria o seu lugar na necessária revisitação do tema das drogas nas culturas juvenis.

\section{Referências bibliográficas}

Abreu, Paula; Silva, Augusto Santos; Guerra, Paula; Moreira, Tânia; Oliveira, Ana (2016),

"The Social Place of Portuguese Punk Scene: An Itinerary of the Social Profiles of its Protagonists", Volume! (no prelo).

Agra, Cândido da (2009), "Requiem pour la guerre à la drogue", Déviance et société, 33, 27-49.

Beck, Ulrich (1992), Risk Society: Towards a New Modernity. New Delhi: Sage.

Becker, Howard S. (1985), Outsiders: Études de la sociologie de la déviance. Paris: Métailié.

Bennett, Andy; Peterson, Richard A. (orgs.) (2004), Music Scenes: Local, Translocal and Virtual. Nashville: Vanderbilt University Press.

Brake, Mike (1985), Comparative Youth Culture: The Sociology of Youth Cultures and Youth Subcultures in America, Britain, and Canada. London: Routledge.

Carvalho, Maria do Carmo (2007), Culturas juvenis e novos usos de drogas em meio festivo: o transe psicadélico como analisador. Porto: Campo das Letras.

Chaves, Miguel (1999), Casal Ventoso: da gandaia ao narcotráfico. Marginalidade económica e dominação simbólica em Lisboa. Lisboa: Instituto de Ciências Sociais. 
Cohen, Stanley (2002), Folk Devils and Moral Panics: The Creation of the Mods and Rockers. London: Routledge.

Costa, Eduardo (1998), "Direito Penal da droga: breve história de um fracasso”, Revista do Ministério Público, 74, 103-120.

Cunha, Ivone (2002), Entre o bairro e a prisão: Tráfico e trajectos. Lisboa: Fim de Século.

Dias, Lúcia Nunes (2007), As drogas em Portugal: o fenómeno e os factos jurídico-políticos de 1970 a 2004. Coimbra: Pé de Página.

Fernandes, Luís; Silva, Rosário (2009), O que a droga fez à prisão - um percurso a partir das terapias de substituição opiácea. Lisboa: Instituto da Droga e da Toxicodependência.

Fernandes, Luís; Ramos, Alexandra (2010), "Exclusão social e violências quotidianas em 'bairros degradados': etnografia das drogas numa periferia urbana”, Toxicodependências, 16, 15-29.

Giddens, Anthony (1991), Modernity and Self-identity. Self and Society in the Late Modern Age. Cambridge: Polity Press.

Guerra, Paula (2014), "Punk, Expectations, Breaches and Metamorphoses: Portugal, 1977-2012”, Critical Arts, 28(1), 111-122.

Guerra, Paula; Quintela, Pedro (2015), "Spreading the Message! Fanzines and the Punk Scene in Portugal”, Punk \& Post Punk, 3(3), 203-224.

Guerra, Paula; Silva, Augusto Santos (2015), "Music and More than Music: The Approach to Difference and Identity in the Portuguese Punk", European Journal of Cultural Studies, 18(2), 207-223.

Guerra, Paula; Bennett, Andy (2015), "Never Mind the Pistols? The Legacy and Authenticity of the Sex Pistols in Portugal”, Popular Music and Society, 38(4), 500-521.

Goffman, Erving (1963), Stigma: Notes on the Management of Spoiled Identity. London: Penguin.

Haenfler, Ross (2006), Straight Edge: Clean-living youth, Hardcore Punk, and Social Change. New Brunswick, New Jersey/London: Rutgers University Press.

Hebdige, Dick (2002), Subculture: The Meaning of Style. London: Routledge [ed. orig.: 1979].

Hodkinson, Paul; Deicke, Wolfgang (2009), Youth Cultures: Scenes, Subcultures and Tribes. London: Routledge.

Inglis, Ian (2007), “'Sex and Drugs and Rock 'n' roll': Urban Legends and Popular Music", Popular Music and Society, 30(5), 591-603.

Marques, Ana Rita (2008), A(s) droga(s) e a(s) toxicodependência(s): representações sociais e políticas em Portugal. Porto: Faculdade de Economia da Universidade do Porto.

Poiares, Carlos Alberto (1995), "A legislação penal da droga: contribuição para uma análise do discurso do legislador”, Toxicodependências, 3, 17-29.

Savage, Jon (2002), England's Dreaming: Les Sex Pistols et le punk. Paris: Éditions Allia.

Silva, Augusto Santos; Guerra, Paula (2015), As palavras do punk. Lisboa: Alêtheia. 
Straw, Will (1991), "Systems of Articulation, Logics of Change: Communities and Scenes in Popular Music”, Cultural Studies, 5(3), 368-388.

Valentim, Artur (2000), "O campo da droga em Portugal: medicalização e legitimação na construção do interdito”, Análise Social, 153, 1007-1042.

\section{Discografia}

Kú de Judas (1996), As histórias da minha avó, V. A., Vozes da Raiva vol. 3. Lisboa: Fast'n'Loud. Compilação (CD).

Kú de Judas (1996), Já estou farto, Vozes da Raiva vol. 3. Lisboa: Fast'n’Loud. Compilação (CD).

Kú de Judas (1996), Sniff Bostik, Vozes da Raiva vol. 3. Lisboa: Fast'n’Loud. Compilação (CD).

Mata-Ratos (1999), Festa tribal, Sente o ódio. Lisboa: Alarm! Records. Álbum (CD).

Motornoise (2007), Podre de bêbedo, Motornoise. Álbum (CD).

Peste \& Sida (1987), Carraspana, Veneno. Lisboa: Schiu! Álbum (Vinil).

Peste \& Sida (1989), Chuta cavalo, Portem-se bem. Lisboa: Polygram. Álbum (Vinil).

Stratus (1982), Um chuto no quarto, Um chuto no quarto. Lisboa: Vimúsica. Single (Vinil).

Trinta e Um (1999), O cavalo mata. Lisboa: Rastilho Records. Álbum (CD).

UHF (1979), Jorge Morreu, Jorge Morreu. Lisboa: Metro-Som. Single (Vinil).

Vómito (1988), Putos da rua, 30 minutos com.... Demo (Cassete).

Artigo recebido a 30.03.2015

Aprovado para publicação a 17.01.2016

\section{Paula Guerra}

Faculdade de Letras da Universidade do Porto Via Panorâmica, s/n, 4150-564 Porto, Portugal Contacto: pguerra@letras.up.pt

\section{Tânia Moreira}

Faculdade de Letras da Universidade do Porto Via Panorâmica, s/n, 4150-564 Porto, Portugal

Contacto: tmoreira@letras.up.pt

\section{Augusto Santos Silva}

Faculdade de Economia da Universidade do Porto

Rua Roberto Frias, s/n, 4200-464 Porto, Portugal

Contacto: asilva@fep.up.pt 


\section{Stigma, Experimentation and Risk:} Alcohol and Drugs in the Punk Scene

Drugs are essential references in rock ' $n$ ' roll in general and punk in particular. The recurring presence of alcohol and drugs in the songs and discourse of key figures from Portuguese punk is not, therefore, accidental. This article considers the issue less from the point of view of practices and contexts associated with their consumption and more from the perspective of the discourses produced within the scene that explore the meaning of their use and the risk of addiction. It draws on empirical material comprising statements from 214 punk actors interviewed between 2012 and 2014 and the lyrics of what they consider to be the most influential songs. It addresses three main issues: 1 ) the representation of the nature of the relationship with alcohol and drugs; 2) its central position as an identity issue, i.e. regarding name, cohesion and position within the scene; 3 ) the diverse attitudes and discourses circulating within it.

Keywords: Portuguese music; punk rock music; rock music; sociology of music; youth cultures.
Stigmate, essai et risque: La question de l'alcool et des drogues dans la scène punk

Les drogues constituent des axes référentiels du rock ' $n$ ' roll en général et du punk rock en particulier. Dès lors, la présence réitérée de l'alcool et des drogues dans les discours des protagonistes et dans les chansons du punk portugais n'est pas casuelle. Cet article s'y penche moins du point de vue des pratiques et des contextes de consommation que du point de vue des discours produits, dans le cadre de la scène, sur le sens de l'usage et de la dépendance. Le matériel empirique sur lequel il repose est constitué par les déclarations de 214 acteurs punk interviewés entre 2012 e 2014; et par les paroles des chansons qu'ils tiennent comme les plus influentes de la scène. L'article aborde trois sujets centraux: 1) la représentation de la nature de la relation avec l'alcool et les drogues; 2) sa centralité comme question identitaire, c'est-à-dire, se rapportant au nom, à la cohésion et au positionnement de la scène; et 3) la diversité des attitudes et des discours qui y circulent.

Mots-clés: cultures juvéniles; musique portugaise; musique punk rock; musique rock; sociologie de la musique. 